\title{
Diabetes prevalence and outcomes in hospitalized cardiorenal-syndrome patients with and without hyponatremia
}

\author{
Rainer U. Pliquett ${ }^{12^{*}}$ D, Katrin Schlump ${ }^{1}$, Andreas Wienke ${ }^{3}$, Babett Bartling ${ }^{4}$, Michel Noutsias ${ }^{5}$,
} Alexander Tamm ${ }^{5,6}$ and Matthias Girndt ${ }^{1}$

\begin{abstract}
Background: Hyponatremia is known to be associated with a worse patient outcome in heart failure. In cardiorenal syndrome (CRS), the prognostic role of concomitant hyponatremia is unclear. We sought to evaluate potential risk factors for hyponatremia in patients with CRS presenting with or without hyponatremia on hospital admission.

Methods: In a retrospective study, we investigated 262 CRS patients without sepsis admitted to the University Hospital Halle over a course of 4 years. CRS diagnosis was derived from an electronic search of concomitant diagnoses of acute or chronic (NYHA 3-4) heart failure and acute kidney injury (AKIN 1-3) or chronic kidney disease (KDIGO G3-G5 nonD). A verification of CRS diagnosis was done based on patient records. Depending on the presence $(\mathrm{Na}<135 \mathrm{mmol} / \mathrm{L}$ ) or absence ( $\mathrm{Na} \geq 135 \mathrm{mmol} / \mathrm{L})$ of hyponatremia on admission, the CRS patients were analyzed for comorbidities such as diabetes, presence of hypovolemia on admission, need for renal replacement therapy and prognostic factors such as in-hospital and one-year mortality.

Results: Two hundred sixty-two CRS patients were included in this study, thereof, 90 CRS patients (34.4\%) with hyponatremia ( $\mathrm{Na}<135 \mathrm{mmol} / \mathrm{L}$ ). The diabetes prevalence among CRS patients was high $(>65 \%)$ and not related to the serum sodium concentration on admission. In comparison to non-hyponatremic CRS patients, the hyponatremic patients had a lower serum osmolality, hypovolemia was more prevalent $(41.1 \%$ versus $16.3 \%, p<$ 0.001). As possible causes of hypovolemia, diarrhea, a higher number of diuretic drug classes and higher diuretic dosages were found. Hyponatremic and non-hyponatremic CRS patients had a comparable need for renalreplacement therapy (36.7\% versus 31.4\%) during the hospital stay. However, after discharge, relatively more hyponatremic CRS patients on renal replacement therapy switched to a non-dialysis therapy regimen $(50.0 \%$ versus 22.2\%). Hyponatremic CRS patients showed a trend for a higher in-hospital mortality (15.6\% versus 7.6\%, $p=0.054$ ), but no difference in the one-year mortality (43.3\% versus $40.1 \%, p=0.692$ ).

Conclusions: All CRS patients showed a high prevalence of diabetes mellitus and a high one-year mortality. In comparison to non-hyponatremic CRS patients, hyponatremic ones were more likely to have hypovolemia, and had a higher likelihood for temporary renal replacement therapy.
\end{abstract}

Keywords: Cardiorenal syndrome, Diabetes mellitus, Hyponatremia, Hypovolemia

\footnotetext{
* Correspondence: rpliquett@endothel.de

'Department of Internal Medicine II, Martin - Luther University Halle-Wittenberg, Halle (Saale), Germany

2Department of Nephrology \& Diabetology, Carl-Thiem Hospital, Cottbus,

Thiemstrasse 111, 03048 Cottbus, Germany

Full list of author information is available at the end of the article
}

C C The Author(s). 2020 Open Access This article is licensed under a Creative Commons Attribution 4.0 International License, which permits use, sharing, adaptation, distribution and reproduction in any medium or format, as long as you give appropriate credit to the original author(s) and the source, provide a link to the Creative Commons licence, and indicate if changes were made. The images or other third party material in this article are included in the article's Creative Commons licence, unless indicated otherwise in a credit line to the material. If material is not included in the article's Creative Commons licence and your intended use is not permitted by statutory regulation or exceeds the permitted use, you will need to obtain permission directly from the copyright holder. To view a copy of this licence, visit http://creativecommons.org/licenses/by/4.0/ The Creative Commons Public Domain Dedication waiver (http://creativecommons.org/publicdomain/zero/1.0/) applies to the data made available in this article, unless otherwise stated in a credit line to the data. 


\section{Background}

Cardiorenal syndrome (CRS), defined as concurrent acute or chronic heart failure (CHF) and acute kidney injury (AKI) or chronic kidney disease (CKD), is associated with a poor prognosis as the presence of renal disease is a stronger predictor for death CHF patients than the degree of reduced left ventricular ejection fraction (LVEF) [1-3]. In CHF patients, an AKI is a leading cause for an acute decompensation [4]. The term acute "renocardiac" syndrome [5] acknowledges this pathophysiology. A more practical definition [6] differentiates between a severe and a stable, chronic CRS, regardless of the pathophysiology. Animal models of CRS demonstrated the bidirectional nature, where the failure of the one organ system adversely affects the function of the other [7]. The consideration of hypoand hypervolemic states may further differentiate CRS on clinical grounds [8].

Arginine-vasopressin (AVP) is released from the posterior pituitary gland upon changes in osmolality and neurally via baroreceptor-mediated activation due to intraarterial hypovolemia or arterial hypotension, thus representing an adaptive mechanism in CHF [9]. AVP acts on vascular smooth muscle cells via vasopressin $1 \mathrm{~A}$ receptors and on renal collecting-duct cells via vasopressin 2 receptors. In CHF, AVP release occurs in a linear fashion to the functional New York Heart Association (NYHA) class [10]. On the flip side, an inappropriate release of AVP may lead to a dilutional hyponatremia and to a deleterious outcome in CHF [11]. Conversely, hypovolemia, e.g. due to diuretic medication, may lead to hypotension as a trigger for an appropriate non-osmotic AVP release, possibly leading to a dilutional hyponatremia as well. Except for sodium-glucose transporter-2 inhibitors in type-2 diabetes patients [12] and in patients with heart failure with reduced LVEF [13], the use of diuretics has not reduced mortality in CHF. Counterregulators of hypovolemia such as an appropriate AVP release and a sympathetic-nervous-system activation may account for this lack of benefit.

In the present study, possible contributing factors for hyponatremia such as presence of hypovolemia, use of diuretics, sodium deficiency and hyperglycemia [14] were obtained from patient records. Furthermore, the prevalence of hypoglycemia on admission in the diabetics among CRS patients was also analyzed. This is because hypoglycemia has been found to be linked to excess mortality in cardiovascular outcome studies [15], and a poorly-controlled diabetes mellitus is usually characterized by post-hypoglycemic hyperglycemic episodes, which, in turn, may depress serum sodium [14]. As a correlate to the fact that hyponatremic CHF patients have a poorer outcome [16], we hypothesized that hyponatremia in CRS worsens patient outcome.

\section{Methods}

\section{Patients and study design}

In a retrospective observational study, all CRS patients admitted to the University Hospital Halle (Department of Internal Medicine II) over a 4-year period were included according to in- and exclusion criteria. The institutional review board of the Martin-Luther-University HalleWittenberg approved this study (file number 2013-92).

\section{Inclusion criteria}

Acutely decompensated or CHF (NYHA class 3 or 4) accompanied by an AKI, stage 1-3 (AKI Network (AKIN) classification [17]) or by CKD stage $3-5_{\text {nonD }}$ according to Kidney Disease: Improving Global Outcomes (KDIGO) classification [18].

\section{Exclusion criteria}

Diagnosis of a malignant tumor within 5 years except non-melanoma skin tumor, the need for peritoneal or hemodialysis prior to admission or index hospitalization, sepsis with procalcitonin plasma levels $>10 \mathrm{ng} / \mathrm{mL}$.

\section{Diagnosis of cardiorenal syndrome}

CRS diagnosis derived from a search in the electronic medical records of the hospital patient-management software using codes for acute or CHF and AKI or CKD according to the International Statistical Classification of Diseases and Related Health Problems (ICD 10th edition) [19]. In addition, a manual verification of CRS diagnosis based on patients' records was mandatory. The first hospitalization in the study period, where heart failure and kidney disease were coded concomitantly, was regarded as index hospitalization. To differentiate between CKD and AKI, the available serum creatinine up to 3 months prior to the index hospitalization and serum creatinine at discharge were taken into account. AKI classification [16] relied on changes in serum creatinine. Changes in urinary output were not considered. Estimated glomerular filtration rate (eGFR) [20] was provided, when creatinine prior to index hospitalization and/or creatinine at discharge showed a variance of less than $26.5 \mu \mathrm{mol} / \mathrm{l}$, as a steady state of serum creatinine is a prerequisite for eGFR calculation. Echocardiography recordings of the index hospitalization were reevaluated by a cardiologist to ascertain the diagnosis of heart failure and/or to differentiate the diagnosis heart failure with reduced (HFrEF) or with preserved ejection fraction. The biplane calculation of LVEF was mandated to qualify for either form of $\mathrm{CHF}$ and the diastolic ventricular function was assessed using the $\mathrm{E} / \mathrm{E}^{\prime}$ ratio.

\section{Analysis}

Analysis relied on patient cohorts with presence $(\mathrm{Na}<$ $135 \mathrm{mmol} / \mathrm{L})$ or absence of hyponatremia ( $\mathrm{Na} \geq 135$ 
$\mathrm{mmol} / \mathrm{L}$ ) on admission. For further analysis, the hyponatremia cohort was divided into subgroups of mild $(\mathrm{Na}<$ $135 \mathrm{mmol} / \mathrm{L}, \quad \mathrm{Na} \geq 130 \mathrm{mmol} / \mathrm{L})$, moderate $(\mathrm{Na}<130$ $\mathrm{mmol} / \mathrm{L}, \mathrm{Na} \geq 125 \mathrm{mmol} / \mathrm{L}$ ), and severe hyponatremia $(\mathrm{Na}<125 \mathrm{mmol} / \mathrm{L})$. Information on the presence or absence of hypovolemia at admission (recorded findings of "exsiccosis", "dehydratation" or "hypovolemia" based on clinical signs including reduced tongue moisture and/or reduced skin turgor and/or sonographic evidence for an inferior vena cava collapsibility [21]), the use and, if applicable, the dosage of diuretics, presence or absence of diarrhea on admission and of diabetes mellitus were collected from patient records. In case of diabetes, the presence or absence of a hypoglycemic episode on admission was determined. Hypoglycemia was assumed, if capillary blood glucose was $<3.9 \mathrm{mmol} / \mathrm{L}$. Additional laboratory results gathered within $24 \mathrm{~h}$ hours after admission were serum procalcitonin, C-reactive protein, creatinine, urea, brain natriuretic peptide, hemoglobin A1c (HbA1c), osmolality, fasting capillary-blood glucose, urinary sodium concentration and urinary sodium excretion over $24 \mathrm{~h}$. If laboratory values were below the lower detection limit, then the lower detection limit was used for analysis.

Outcome parameters were length of the hospital stay, in-hospital and one-year mortality, need for temporary $(<$ 1 year) and chronic (> 1 year) peritoneal or hemodialysis. Resident's registration offices of patients' home towns were contacted to provide information on the date of death, if applicable, for up to 2 years after discharge in index hospitalization.

\section{Statistics}

Data were given as mean with standard deviation or as the absolute number and percentage of all patients. The Kolmogorov-Smirnov test was used to check for normal distribution of the values. Differences between the mean values of two evaluation groups have been checked by Student's t test (parametric data) or Mann-Whitney test (nonparametric data) and of more than two evaluation groups by the ANOVA test (parametric data) or Kruskal-Wallis test (non-parametric data) with post-hoc tests (Tukey or Dunn, where appropriate). Cox regression analysis was used for the determination of in-hospital and one-year mortality, Kaplan-Meier method with log-rank test for survival analysis. All data calculations were performed by use of the SPSS software (version 21; IBM Corp., Armonk, New York, USA). Graphs were displayed using the Graphpad software (Prism 8, La Jolla, California, USA).

\section{Results}

Three hundred eighty-six data sets of CRS patients were identified when analyzing electronic medical records using the prespecified diagnosis codes for the study period. After a manual verification, 124 patients were excluded for one or more applicable exclusion criteria: sepsis $(n=7)$, malignancies $(n=47)$, an ongoing or prior hemodialysis treatment $(n=63)$, or absence of CHF $(n=$ 11). The characteristics of the included 262 CRS patients with and without hyponatremia on admission are provided in Table 1. Of note, the hyponatremia cohort had a higher proportion of female patients.

\section{Cardiac and renal function in CRS patients}

LVEF was slightly higher in CRS patients with hyponatremia on admission than without (Table 1). CRS patients with moderate-to-severe hyponatremia on admission had a more preserved systolic function in comparison to the ones without hyponatremia or mild hyponatremia on admission (Fig. 1). Diastolic left ventricular dysfunction was highly prevalent in both cohorts $(98.9 \%$ in hyponatremic, $98.3 \%$ in nonhyponatremic CRS patients). No echocardiography follow-up exams were available. An AKI occurred in more hyponatremic than non-hyponatremic CRS patients, while CKD was less frequently diagnosed in hyponatremic versus non-hyponatremic ones (Table 1). Prior to index hospitalization, an arteriovenous fistula as a preemptive vascular access was placed in a larger proportion of non-hyponatremic CRS patients than hyponatremic ones (Table 1).

\section{Prevalence and causes of hyponatremia in CRS patients}

On admission, $34.4 \%$ of CRS patients presented with hyponatremia. Among them, 9 (3.4\%) patients had a severe, $22(8.4 \%)$ patients a moderate, and $59(22.5 \%)$ patients a mild hyponatremia on admission. In 7 (2.7\%) non-hyponatremic CRS patients, a hypernatremia (maximum Na: $150 \mathrm{mmol} / \mathrm{L}$ ) was found. As Fig. 2 demonstrates, hyponatremia correlated with serum osmolality in terms of a hyposmolar hyponatremia. A reduced urinary-sodium concentration $(<30 \mathrm{mmol} / \mathrm{L})$ was found in $5(5.6 \%)$ patients of the hyponatremic cohort versus 6 (3.5\%) patients of the non-hyponatremic cohort. Likewise, collecting urine measurements showed a reduced urinary sodium excretion of less than $100 \mathrm{mmol} / \mathrm{d}$ (equaling $6 \mathrm{~g} / \mathrm{d}$ sodium chloride) in 13 or $14.4 \%$ of hyponatremic versus 14 or $8.1 \%$ of non-hyponatremic CRS patients. As a contrasting finding, urinary sodium wasting (sodium excretion of $>300 \mathrm{mmol} / \mathrm{d}$ or $>18 \mathrm{~g} / \mathrm{d}$ sodium chloride) was seen more often in the hyponatremia (26\%) than in the non-hyponatremia cohort (13\%).

Hypovolemia was more frequently encountered in hyponatremic than in non-hyponatremic CRS patients (Fig. 3). Thee prevalence of diarrhea, the number of prescribed diuretic drug classes and, if applicable, the dosages of hydrochlorothiazide and furosemide were the possible underlying reasons accounting for the observations made. (Table 1). Diarrhea on admission was more frequently present in CRS patients both with mild (9 of 59 or $15.3 \%$ ) and moderate-to-severe hyponatremia (7 of 
Table 1 Characteristics of 262 CRS patients with and without hyponatremia at hospital admission

\begin{tabular}{|c|c|c|c|c|c|c|c|c|c|}
\hline & \multicolumn{4}{|c|}{ CRS patients with hyponatremia ${ }^{a}$} & \multicolumn{5}{|c|}{ CRS patients without hyponatremia $^{a}$} \\
\hline & $\% n$ & $\mathrm{n}$ & mean $\pm S D$ & $\mathrm{n}^{\mathrm{b}}$ & $\% \mathrm{n}$ & $\mathrm{n}$ & mean $\pm S D$ & $n^{b}$ & $p$ value \\
\hline \multicolumn{10}{|l|}{ Patient characteristics } \\
\hline Men (n) & 36.7 & 33 & & 90 & 52.3 & 90 & & 172 & 0.019 \\
\hline Women (n) & 63.3 & 57 & & 90 & 47.7 & 82 & & 172 & \\
\hline Age (years) & & 90 & $74.0 \pm 13.0$ & 90 & & & $73.8 \pm 13.0$ & 172 & 0.768 \\
\hline Body mass index $\left(\mathrm{kg} / \mathrm{m}^{2}\right)$ & & 41 & $30.2 \pm 8.1$ & 90 & & 98 & $30.3 \pm 7.3$ & 172 & 0.709 \\
\hline Hypovolemia & 41.1 & 37 & & 90 & 16.3 & 28 & & 172 & $<0.0001$ \\
\hline Diarrhea (n) & 17.8 & 16 & & 90 & 5.2 & 9 & & 172 & 0.002 \\
\hline Classes of oral diuretics per patient (n) & & 88 & $1.6 \pm 1.0$ & 90 & & 161 & $1.3 \pm 0.7$ & 172 & 0.003 \\
\hline Torasemide (mg/d) & & 68 & $23.1 \pm 49.0$ & 90 & & 57 & $19.2 \pm 28.0$ & 172 & 0.612 \\
\hline Furosemide (mg/d) & & 70 & $34.4 \pm 135.8$ & 90 & & 62 & $1.9 \pm 7.9$ & 172 & 0.003 \\
\hline Hydrochlorothiazide (mg/d) & & 71 & $7.7 \pm 11.5$ & 90 & & 57 & $2.2 \pm 6.3$ & 172 & 0.002 \\
\hline Xipamide (mg/d) & & 67 & $4.3 \pm 16.4$ & 90 & & 62 & $0.8 \pm 3.3$ & 172 & 0.159 \\
\hline Spironolactone (mg/d) & & 69 & $13.8 \pm 38.2$ & 90 & & 63 & $5.0 \pm 17.9$ & 172 & 0.109 \\
\hline Eplerenone (mg/d) & & 70 & $1.1 \pm 5.1$ & 90 & & 63 & $1.4 \pm 5.6$ & 172 & 0.707 \\
\hline \multicolumn{10}{|l|}{ Laboratory parameters } \\
\hline $\mathrm{Na}$ (serum, mmol/L) & & 90 & $129.6 \pm 5.1$ & 90 & & 172 & $139.4 \pm 3.0$ & 172 & $<0.0001$ \\
\hline $\mathrm{Na}$ at discharge (serum, mmol/L) & & 23 & $136.5 \pm 4.3$ & 75 & & 16 & $139.0 \pm 3.9$ & 136 & $<0.0001$ \\
\hline $\mathrm{Na}$ (urine, $\mathrm{mmol} / \mathrm{L}$ ) & & 37 & $68.2 \pm 34.5$ & 90 & & 76 & $78.3 \pm 30.0$ & 172 & 0.113 \\
\hline $\mathrm{Na}$ (collecting urine, $\mathrm{mmol} / 24 \mathrm{~h}$ ) & & 31 & $191.0 \pm 163.8$ & 90 & & 63 & $185.5 \pm 109.2$ & 172 & 0.477 \\
\hline Urea (serum, mmol/L) & & 87 & $26.3 \pm 14.6$ & 90 & & 160 & $22.4 \pm 16.1$ & 172 & 0.006 \\
\hline Cystatin C (serum, mg/mL) & & 25 & $2.7 \pm 1.0$ & 90 & & 46 & $2.7 \pm 1.1$ & 172 & 0.827 \\
\hline Creatinine prior to hospitalization (serum, $\mu \mathrm{mol} / \mathrm{L}$ ) & & 53 & $148.8 \pm 61.3$ & 90 & & 96 & $171.1 \pm 107.0$ & 172 & 0.251 \\
\hline Creatinine (serum, $\mu \mathrm{mol} / \mathrm{L}$ ) & & 90 & $300.7 \pm 205.8$ & 90 & & 172 & $285.5 \pm 256.1$ & 172 & 0.147 \\
\hline Osmolality, calculated (serum, mosm/kg) & & 52 & $295.6 \pm 22.2$ & 90 & & 93 & $308.4 \pm 18.9$ & 172 & 0.0002 \\
\hline C-reactive protein (serum, mg/L) & & 89 & $57.8 \pm 75.0$ & 90 & & 172 & $54.5 \pm 80.4$ & 172 & 0.308 \\
\hline Procalcitonine (serum, pg/mL) & & 24 & $1.7 \pm 2.6$ & 90 & & 38 & $1.0 \pm 1.9$ & 172 & 0.680 \\
\hline \multicolumn{10}{|l|}{ Renal and cardiac parameters } \\
\hline Acute kidney injury & 71.1 & 64 & & 90 & 45.9 & 79 & & 172 & \\
\hline AKIN 1 & 48.4 & 31 & & 64 & 31.6 & 25 & & 79 & \\
\hline AKIN 2 & 11.0 & 7 & & 64 & 15.2 & 12 & & 79 & \\
\hline AKIN 3 & 40.6 & 26 & & 64 & 53.2 & 42 & & 79 & \\
\hline Chronic kidney disease & 28.9 & 26 & & 90 & 54.1 & 93 & & 172 & \\
\hline KDIGO 1-3 & 42.3 & 11 & & 26 & 52.6 & 49 & & 93 & \\
\hline KDIGO 4 & 19.2 & 5 & & 26 & 23.7 & 22 & & 93 & \\
\hline KDIGO 5 & 38.5 & 10 & & 26 & 23.7 & 22 & & 93 & \\
\hline Estimated glomerular filtration rate, if steady state $\left(\mathrm{mL} / \mathrm{min} / 1.73 \mathrm{~m}^{2}\right)$ & & 26 & $27.9 \pm 19.8$ & 90 & & 93 & $31.7 \pm 20.1$ & 172 & 0.403 \\
\hline arteriovenous fistula, preexisting (n) & 5.5 & 5 & & 90 & 14.5 & 25 & & 172 & 0.017 \\
\hline Left ventricular ejection fraction (\%) & & 56 & $48.5 \pm 12.7$ & 90 & & 102 & $44.4 \pm 13.4$ & 172 & 0.046 \\
\hline Brain natriuretic peptide (serum, pg/mL) & & 56 & $1321.0 \pm 1851.0$ & 90 & & 117 & $1319.0 \pm 1725.0$ & 172 & 0.940 \\
\hline \multicolumn{10}{|l|}{ Diabetes-related parameters } \\
\hline Diabetes mellitus ( $\mathrm{n}$ ) & 66.7 & 60 & & 90 & 65.7 & 113 & & 172 & 0.892 \\
\hline - insulin- dependent (n) & 65.0 & 39 & & 60 & 66.4 & 75 & & 113 & 0.973 \\
\hline - oral antidiabetics (n) & 8.3 & 5 & & 60 & 11.5 & 13 & & 113 & 0.608 \\
\hline
\end{tabular}


Table 1 Characteristics of 262 CRS patients with and without hyponatremia at hospital admission (Continued)

\begin{tabular}{|c|c|c|c|c|c|c|c|c|c|}
\hline & \multicolumn{4}{|c|}{ CRS patients with hyponatremia ${ }^{a}$} & \multicolumn{5}{|c|}{ CRS patients without hyponatremia $^{a}$} \\
\hline & $\% n$ & $\mathrm{n}$ & mean \pm SD & $\mathrm{n}^{\mathrm{b}}$ & $\% n$ & $\mathrm{n}$ & mean $\pm S D$ & $n^{\mathrm{b}}$ & $p$ value \\
\hline - diet alone (n) & 26.7 & 16 & & 60 & 22.1 & 25 & & 113 & 0.574 \\
\hline Glucose on admission, non-fasting (capillary blood, mmol/L) & & 51 & $9.6 \pm 6.6$ & 90 & & 96 & $7.7 \pm 3.5$ & 172 & 0.063 \\
\hline Glucose, fasting (capillary blood, mmol/L) & & 15 & $7.5 \pm 2.6$ & 90 & & 27 & $6.7 \pm 1.7$ & 172 & 0.209 \\
\hline HbA1c (\%) & & 28 & $7.6 \pm 2.6$ & 90 & & 47 & $6.6 \pm 0.8$ & 172 & 0.235 \\
\hline Hypoglycemia (symptomatic) on admission (n) & 8.9 & 8 & & 90 & 4.6 & 8 & & 172 & 0.184 \\
\hline \multicolumn{10}{|l|}{ Outcome parameters } \\
\hline Hospitalization (days) & & & $16.5 \pm 11.0$ & 76 & & 159 & $18.5 \pm 16.5$ & 172 & 0.905 \\
\hline new-onset hemodialysis (in hospital, n) & 36.7 & 33 & & 90 & 31.4 & 54 & & 172 & 0.409 \\
\hline chronic dialysis ${ }^{c}(\mathrm{n})$ & 19.6 & 10 & & 51 & 27.0 & 27 & & 103 & 0.104 \\
\hline Death in hospital (n) & 15.6 & 14 & & 90 & 7.6 & 13 & & 172 & 0.054 \\
\hline One-year mortality (n) & 43.3 & 39 & & 90 & 40.1 & 69 & & 172 & 0.692 \\
\hline
\end{tabular}

${ }^{a}$ hyponatremia at a serum $\mathrm{Na}$ concentration of $<135 \mathrm{mmol} / \mathrm{L}$

${ }^{b}$ final number of CRS patients subjected to statistical analysis. This number can be lower than the maximum number due to the lack of data

${ }^{c}$ hemodialysis or peritoneal dialysis

31 or $22.6 \%$ ) than in non-hyponatremic ones ( 9 of 172 or $5.2 \%, p=0.0025)$.

High prevalence of type-2 diabetes among CRS patients Prevalence of diabetes mellitus on admission was equally high in CRS patients with (66.7\%) versus CRS patients

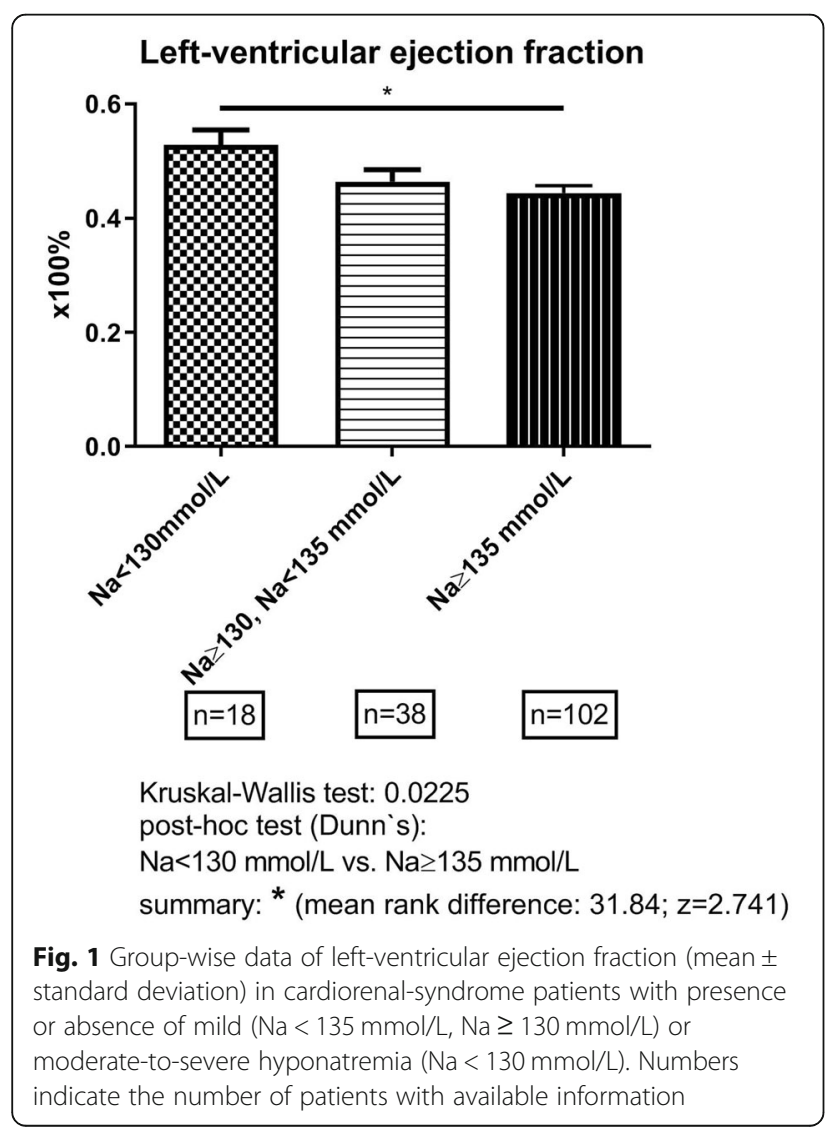

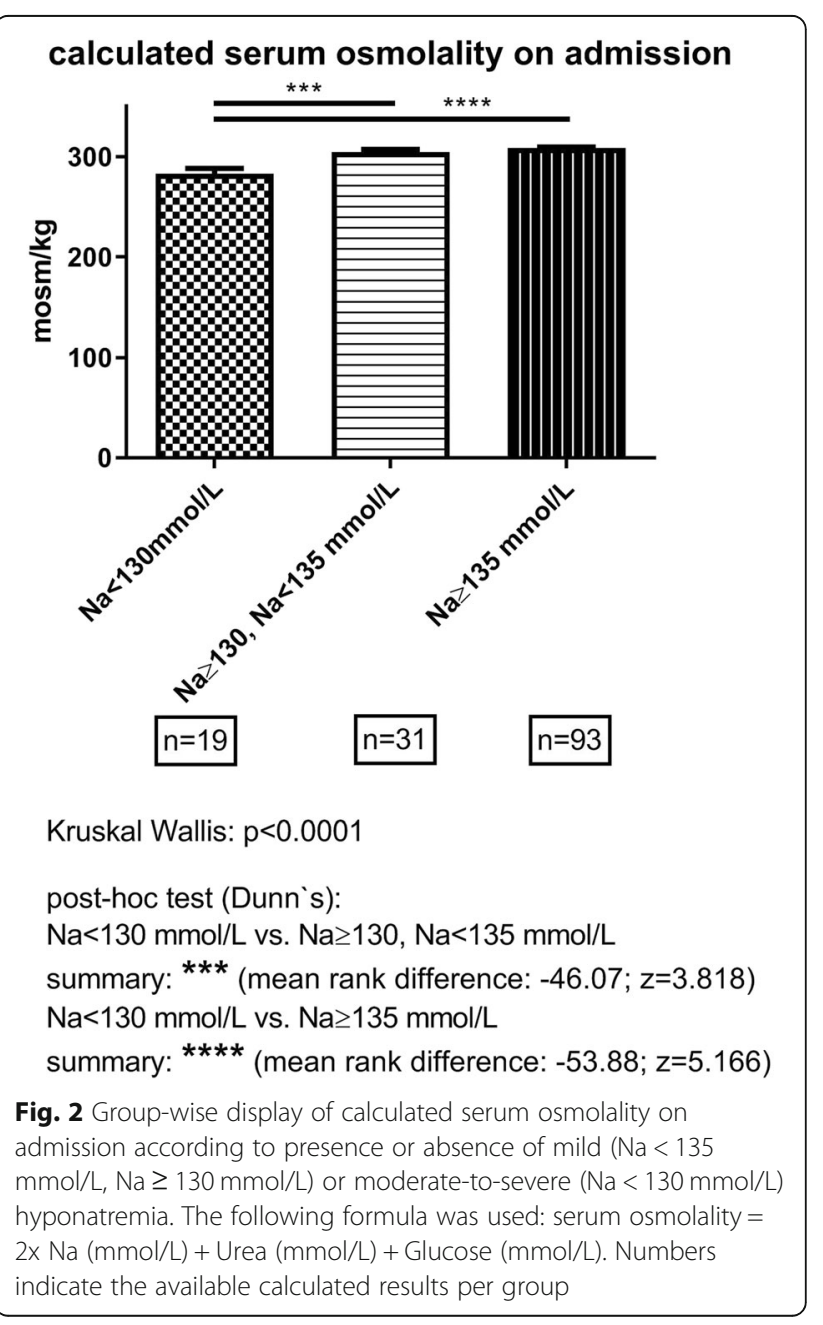




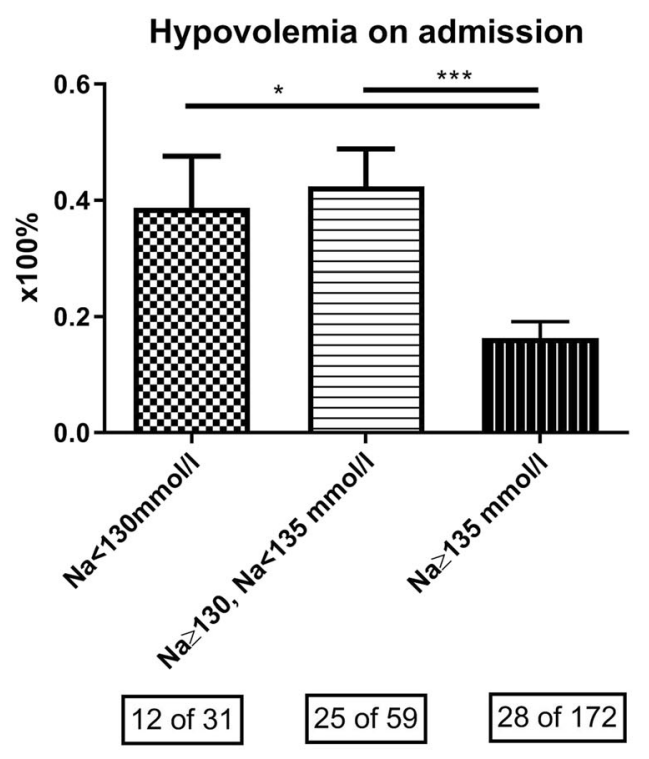

Kruskal Wallis: $p<0.0001$

\begin{tabular}{|c|c|c|c|}
\hline Dunn's multiple comparisons test & Mean rank diff. & Significant? & Summary \\
\hline $\mathrm{Na}<130 \mathrm{mmol} / \mathrm{l}$ vs. $\mathrm{Na} 130, \mathrm{Na}<135 \mathrm{mmol} / \mathrm{l}$ & -4.799 & No & ns \\
\hline $\mathrm{Na}<130 \mathrm{mmol} / \mathrm{l}$ vs. $\mathrm{Na} 135 \mathrm{mmol} / \mathrm{l}$ & 29.38 & Yes & * \\
\hline $\mathrm{Na} \geq 130, \mathrm{Na}<135 \mathrm{mmol} / \mathrm{lvs} . \mathrm{Na} \geq 135 \mathrm{mmol} / \mathrm{l}$ & 34.18 & Yes & *** \\
\hline
\end{tabular}

Fig. 3 Group-wise display of clinical signs of hypovolemia on admission according to presence or absence of mild ( $\mathrm{Na}<135 \mathrm{mmol} / \mathrm{L}, \mathrm{Na} \geq 130$ $\mathrm{mmol} / \mathrm{L}$ ) or moderate-to-severe $(\mathrm{Na}<130 \mathrm{mmol} / \mathrm{L}$ ) hyponatremia. Numbers indicate the absolute number of patients with hypovolemia and the total number of patients with available information

without hyponatremia $(65.7 \%)$ on admission, while the prevalence in the background population of the hospital referral region was $12 \%$ [22]. The majority of diabetic CRS patients had a type-2 diabetes, except for 10 (14.4\%) patients of the hyponatremia cohort and 13 (11.5\%) of the non-hyponatremia cohort who had a type-1 diabetes, a steroid-related or a new-onset diabetes after transplant. A steroid therapy, either via oral or inhalation route, was applied in $24.7 \%$ of hyponatremic and in $28.8 \%$ of non-hyponatremic CRS patients respectively. An immunosuppressive regimen for a functioning kidney transplant was applied in $4.4 \%$ versus $3.5 \%$ of hyponatremic versus non-hyponatremic CRS patients. The proportion of insulin-dependent diabetes, the percentage of patients presenting with a symptomatic hypoglycemia on admission (Table 1) and, if applicable, the cumulative daily insulin dose ( $49.7 \pm 47.7$ units/d versus $52.1 \pm 37.4$ units/d, $p=0.369$ ), were not different between CRS patients with and without hyponatremia. Likewise, the average insulin dose per body weight $(0.64 \pm 0.66$ units $/ \mathrm{kg}$ versus $0.59 \pm 0.33$ units $/ \mathrm{kg})$ was not different between hyponatremic versus nonhyponatremic CRS patients. With regard to non-insulin therapy of type- 2 diabetes, only one diabetes patient of the hyponatremia cohort was treated with incretin mimetics in addition to insulin, none was treated with sodium-glucose-transporter-2 inhibitors.

\section{Outcomes of CRS patients with and without hyponatremia}

The length of hospital stay (Table 1) and survival (Fig. 4) were not different between hyponatremic versus nonhyponatremic CRS patients. In non-hyponatremic CRS patients, median survival was 17.4 (range: 0.004 to 65.2 ) months, while it was, 12.5 (range: 0.049 to 63.9 ) months in mildly hyponatremic, and 13.5 (range: 0.278 to 64.1 ) months in moderate-to-severe hyponatremic CRS patients. One-year mortality was high both in CRS patients with $(43.3 \%)$ and without (40.1\%) hyponatremia on admission. Lastly, in-hospital mortality was higher among hyponatremic (15.6\%) than among non-hyponatremic (7.6\%) patients (Table 1 ).

Age on admission (hazard ratio: $1.05 ; p<0.001$ ). 6 and male sex (hazard ratio: 1.48; $p=0.02$ ) were predictors for mortality. Even though one-year mortality was not different between groups, a subgroup analysis with a cut off at an age of 60 years was performed. A comparable one-year mortality was found in CRS patients being older than 60 years $(45.3 \%$ versus $45.4 \%$ in hypo- versus nonhyponatremic CRS patients). However, hyponatremic CRS 


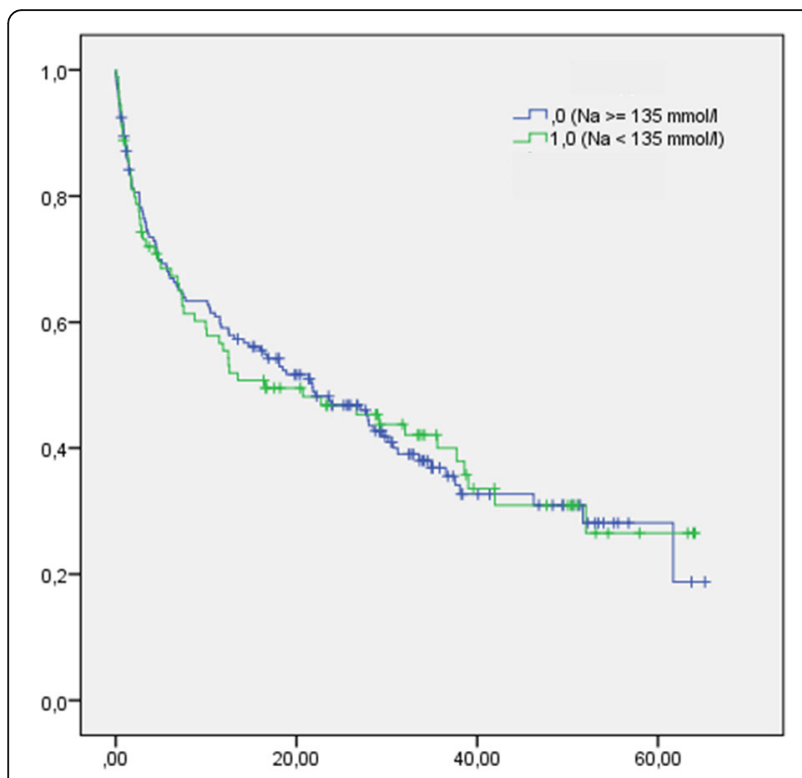

Fig. 4 Survival data of CRS patients with $(\mathrm{Na}<135 \mathrm{mmol} / \mathrm{L})$ and without ( $\mathrm{Na} \geq 135 \mathrm{mmol} / \mathrm{L}$ ) hyponatremia

patients being less than 60 years had a higher one-year mortality (40.6\%) than its non-hyponatremic counterparts (9.6\%). At discharge, $30.7 \%$ of the initial hyponatremia cohort and $11.8 \%$ of the initial non-hyponatremia cohort presented with mild or moderate hyponatremia. Within 1 year after discharge, 8 (10.7\%) persistently hyponatremic patients of the initial hyponatremic cohort and 6 (4.4\%) hyponatremic patients of the initial non-hyponatremia cohort died.

As for renal replacement therapy, hemodialysis therapy was chosen, if needed, during index hospitalization (Table 1). By discharge, the proportion of patients on hemodialysis was comparable between groups: 26 (34.2\%) surviving patients of the hyponatremia cohort and $49(30.8 \%)$ surviving patients of the non-hyponatremia cohort were placed on an intermittent hemodialysis schedule (thrice-a-week). None of the hyponatremia cohort, but 2 (1.2\%) patients of the nonhyponatremia cohort switched to peritoneal dialysis within 1 year after discharge. Among CRS patients without renalreplacement therapy during index hospitalization, 1 out of 76 (or 1.3\%) in the hyponatremia cohort and 3 out of 159 (or 1.9\%) in the non-hyponatremia cohort initiated hemodialysis after discharge during the following year. Within 1 year after discharge, $50.0 \%$ of hyponatremic versus $22.2 \%$ of non-hyponatremic CRS patients on renal replacement therapy switched to a conservative therapy regimen without hemo- or peritoneal dialysis.

\section{Discussion}

As main findings, CRS patients included in this study had both a high prevalence of diabetes mellitus and a high one-year mortality, regardless of serum sodium concentration on admission. So far, this is the first report showing a diabetes prevalence of more than $65 \%$ in consecutively hospitalized CRS patients. However, there was no relation between hyperglycemia and hyponatremia in CRS patients. The finding of an exceedingly increased one-year mortality of CRS patients is in line with previous evidence [23]. Therefore, as hospitalizations for CRS greatly increased by up to $17 \%$ in internalmedicine departments in recent years [24], it is of paramount importance to improve the overall outcome of patients with CRS.

\section{Diabetes mellitus as a double-organ risk}

Regarding diabetes mellitus in CRS, diabetes-related vascular sequelae may translate into cardiac and renal dysfunction in terms of a CRS, type 5 [5]. In the literature, CHF patients with diabetes mellitus were shown to have a higher CKD prevalence than CHF patients without diabetes [25]. Likewise, in a recent retrospective study, more than $50 \%$ of CRS patients with incident peritonealdialysis therapy had diabetes mellitus [26]. The current study showed that the mean cumulative daily insulin dose per body weight was higher than expected suggesting an insulin resistance or, alternatively, an over-dosage of insulin. Supporting the first scenario, roughly one quarter of CRS patients of both cohorts was on a steroid therapy. In addition, inflammatory parameters were elevated on admission. As for the latter scenario, the number of symptomatic hypoglycemic episodes on hospital admission was remarkably high in both cohorts. Given a pro-hypoglycemic role of renal dysfunction, an insulinminimizing strategy is warranted in CRS. In addition, as for the proven nephro- and cardio-protection by both incretin mimetics [27] and sodium-glucose cotransporter-2 inhibitors [28] for type-2 diabetes patients, at least incretin mimetics could be used as an alternative to insulin in CRS patients with type-2 diabetes and without need for renal replacement therapy [27]. In acute CRS, sodium glucose cotransporter-2 inhibitors should be considered, when renal function has fully recovered. This drug class has shown a prognostic benefit even in HFrEF patients without diabetes mellitus [13].

\section{Hypovolemia as a main cause of hyponatremia in hospitalized CRS patients}

Although hyponatremia was shown to be multifactorial, in more than one third of hyponatremic CRS patients, there were signs of hypovolemia on admission. Hypovolemia was substantiated by a more frequent history of diarrhea, by more prescribed diuretic drug classes and by higher dosages of prescribed diuretics in the hyponatremia cohort. It remains unclear, whether or not the difference in cardiac systolic function between hyponatremic and non-hyponatremic CRS patients (Fig. 1) was due to a lesser end-diastolic left-ventricular pressure during hypovolemia. The extensive use of diuretics has 
been established as a leading cause for hypovolemia in CRS patients of this study. Here, the dose combinations of several diuretics appear to bear an increased risk for hypovolemia-related hyponatremia or for hyponatremia as a side effect of diuretics. In addition, the use of a diuretic combination therapy favors a rise in serum urea [29]. Besides hypovolemia, the percentage of patients with excessive sodium excretion in 24-h collecting-urine measurements was twice as high in hyponatremic versus nonhyponatremic CRS patients. This result is in line with either renal sodium wasting or increased sodium-chloride consumption. The latter was excluded for the patients of the current study. Conversely, the use of loop diuretics as a cause for sodium depletion is highly likely, as the prescribed furosemide dosage was higher among hyponatremic CRS patients in comparison to non-hyponatremic ones. In addition to sodium depletion, loop diuretics induce a hypovolemia-triggered, appropriate AVP activation [30].

In case of hypervolemia-associated hyponatremia, freewater excess and/or diuretic resistance may apply as pathomechanisms for hyponatremia. Among hypervolemic CRS patients included in this study, a further differentiation based on chloremia was not performed. A diuretic resistance is possible in cases of hypochloremia due to less active chloride-sensitive kinases such as the serine/threonine kinase WNK1 [31]. However, on clinical grounds, a diuretic resistance can be assumed in all patients with new-onset hemodialysis. Comparable proportions of CRS patients with and without hyponatremia experienced new-onset hemodialysis though.

\section{Cardiorenal syndrome with hyponatremia as an acute, amenable condition}

The likelihood for a temporary, not chronic renalreplacement therapy after discharge was higher in the hyponatremia versus non-hyponatremia cohort $(50.0 \%$ versus $22.2 \%$ ). These results are compatible with an acute and amenable condition like AKI or acutely decompensated heart failure in hyponatremic CRS patients. This view is supported by the overall higher incidence of AKI among hyponatremic compared to non-hyponatremic CRS patients, and by the fact that more non-hyponatremic than hyponatremic CRS patients had a preemptive arteriovenous fistula signifying a rather advanced CKD condition there. In retrospect, the placement of arterio-venous fistulae in CRS patients appears to be questionable, as the shunt volume may aggravate heart failure [32].

\section{Outlook and study constraints}

In retrospective, observational studies, causative relationships cannot be established. However, from the current study, a prognostic role for hyponatremia in CRS patients is questioned. With regard to hyponatremia at discharge, the number of study participants was too small to assess a possible prognostic role. More pathophysiological studies are needed to further dissect the underlying mechanisms of hyponatremia in CRS. In addition, randomized clinical trials may help identify new treatment approaches and/or gauge the effect of existing ones for CRS with and without diabetes mellitus. An individualized ambulatory patient care needs to focus on euvolemia as a therapy goal. There, a careful use of diuretics and an adequate diabetes control, if applicable, are crucial. As both peritoneal dialysis [33, 34] and hemodialysis [35] may improve the functional capacity in CHF symptoms, it is subject to future studies to compare these therapy modalities in CRS patients with and without diabetes mellitus.

\section{Conclusions}

As a main result, this study confirms the high death toll among CRS patients both with and without hyponatremia on admission. The finding of a very high prevalence of diabetes mellitus among all CRS patients may increase the awareness for CRS, when diagnosis of diabetes mellitus has been established. Lastly, hyponatremia in CRS patients of this study was shown to be multifactorial, and hyponatremic CRS patients more frequently had an acute decompensation of heart and/or kidney function.

\section{Abbreviations \\ AKIN: Acute kidney injury network; AVP: Arginine vasopressin; CHF: Chronic heart failure; CRS: Cardiorenal syndrome; d: Day(s); eGFR: Estimated glomerular filtration rate; HbA1c: Hemoglobin A1c; HFrEF: Heart failure with reduced ejection fraction; KDIGO : Kidney Disease: Improving Global Outcomes; LVEF: Left ventricular ejection fraction; Na: Sodium; NYHA: New York Heart Association}

\section{Acknowledgements \\ The authors wish to thank Abimbola Adeagbo for proof-reading service.}

Authors' contributions

RUP conceived the study: Both KS and RUP analyzed and interpreted the data. AT and MN performed the cardiologic examination of the data, BB and MG gave critical input to discussion and interpretation of the data. AW supervised statistical analysis. All authors read and approved the final manuscript.

\section{Funding}

For this study, no external source of funding was used. Open access funding provided by Projekt DEAL.

\section{Availability of data and materials \\ The datasets used and/or analyzed during the current study are available from the corresponding author on reasonable request.}

\section{Ethics approval and consent to participate}

The institutional review board of the Martin-Luther-University HalleWittenberg approved this study (file number 2013-92). The need for an individual patient information and signed informed consent was waived. The hospital has not required any further permission to access the medical records of patients of this retrospective study.

Consent for publication

Not applicable.

Competing interests

The authors declare that they have no competing interests. 


\section{Author details}

'Department of Internal Medicine II, Martin - Luther University Halle-Wittenberg, Halle (Saale), Germany. ${ }^{2}$ Department of Nephrology \& Diabetology, Carl-Thiem Hospital, Cottbus, Thiemstrasse 111, 03048 Cottbus, Germany. ${ }^{3}$ Institute of Medical Epidemiology, Biometry and Informatics, Martin-Luther University Halle-Wittenberg, Halle (Saale), Germany. ${ }^{4}$ University Clinic and Outpatient Clinic for Cardiac Surgery, Martin - Luther University Halle-Wittenberg, Halle (Saale), Germany. ${ }^{5}$ nniversity Clinic and Outpatient Clinic for Internal Medicine III, Martin-Luther University Halle-Wittenberg, Halle (Saale), Germany. ${ }^{6}$ Department of Cardiology, University Mainz, Mainz, Germany.

Received: 26 March 2020 Accepted: 20 August 2020

Published online: 10 September 2020

\section{References}

1. Hillege HL, Girbes AR, de Kam PJ, Boomsma F, de Zeeuw D, Charlesworth A, et al. Renal function, neurohormonal activation, and survival in patients with chronic heart failure. Circulation. 2000;102:203-10.

2. Forman DE, Butler J, Wang Y, Abraham WT, O'Connor CM, Gottlieb SS, et al, Incidence, predictors at admission, and impact of worsening renal function among patients hospitalized with heart failure. J Am Coll Cardiol. 2004;43:61-7.

3. Brisco MA, Coca SG, Chen J, Owens AT, McCauley BD, Kimmel SE, et al. Blood urea nitrogen/creatinine ratio identifies a high-risk but potentially reversible form of renal dysfunction in patients with decompensated heart failure. Circ Heart Fail. 2013;6:233-9.

4. Rigopoulos AG, Bakogiannis C, de Vecchis R, Sakellaropoulos S, Ali M, Teren M, Matiakis M, Tschoepe C, Noutsias M. Acute heart failure : an unmet medical need. Herz. 2019;44:53-5.

5. Ronco C, Haapio M, House AA, Anavekar N, Bellomo R. Cardiorenal syndrome. J Am Coll Cardiol. 2008;52:1527-39.

6. Bongartz LG, Cramer MJ, Doevendans PA, Joles JA, Braam B. The severe cardiorenal syndrome: 'Guyton revisited'. Eur Heart J. 2005;26:11-7.

7. Bongartz LG, Braam B, Gaillard CA, Cramer MJ, Goldschmeding R, Verhaar $M C$, et al. Target organ cross talk in cardiorenal syndrome: animal models. Am J Physiol Renal Physiol. 2012;303:F1253-63.

8. Linhart C, Ulrich C, Greinert D, Dambeck S, Wienke A, Girndt M, et al. Systemic inflammation in acute cardiorenal syndrome: an observational pilot study. ESC Heart Fail. 2018:5:920-31.

9. Goldsmith SR, Francis GS, Cowley AW Jr, Levine TB, Cohn JN. Increased plasma arginine vasopressin levels in patients with congestive heart failure. J Am Coll Cardiol. 1983;1:1385-90.

10. Price JF, Towbin JA, Denfield SW, Clunie S, Smith EO, McMahon CJ, et al. Arginine vasopressin levels are elevated and correlate with functional status in infants and children with congestive heart failure. Circulation. 2004;109:2550-3.

11. Rosner MH, Ronco C. Hyponatremia in heart failure: the role of arginine vasopressin and its antagonism. Congest Heart Fail. 2010;16:57-14.

12. Zinman B, Wanner C, Lachin JM, Fitchett D, Bluhmki E, Hantel S, et al. Empagliflozin, cardiovascular outcomes, and mortality in type 2 diabetes. N Engl J Med. 2015;373:2117-28.

13. McMurray JJV, Solomon SD, Inzucchi SE, Køber L, Kosiborod MN, Martinez FA, et al. Dapagliflozin in patients with heart failure and reduced ejection fraction. N Engl J Med. 2019;381:1995-2008.

14. Katz MA. Hyperglycemia-induced hyponatremia - calculation of expected serum sodium depression. N Engl J Med. 1973;289:843-4.

15. Frier BM, Schernthaner G, Heller SR. Hypoglycemia and cardiovascular risks. Diabetes Care. 2011;34(Suppl 2):S132-7.

16. Gheorghiade M, Rossi JS, Cotts W, Shin DD, Hellkamp AS, Pina IL, et al. Characterization and prognostic value of persistent hyponatremia in patients with severe heart failure in the ESCAPE trial. Arch Intern Med. 2007; 167:1998-2005.

17. Mehta RL, Kellum JA, Shah SV, Molitoris BA, Ronco C, Warnock DG, et al. Acute kidney injury network: report of an initiative to improve outcomes in acute kidney injury. Crit Care. 2007;11:R31.

18. Levey AS, Eckardt KU, Tsukamoto Y, Levin A, Coresh J, Rossert J, et al. Definition and classification of chronic kidney disease: a position statement from kidney disease: improving global outcomes (KDIGO). Kidney Int. 2005; 67:2089-100.

19. World Health Organization. International statistical classification of diseases and related health problems10th revision. 2011. ISBN 9789241548342.
20. Levey AS, Stevens LA. Estimating GFR using the CKD epidemiology collaboration (CKD-EPI) Creatinine equation: more accurate GFR estimates, lower CKD prevalence estimates, and better risk predictions. Am J Kidney Dis. 2010;55:622-7.

21. Corl KA, George NR, Romanoff J, Levinson AT, Chheng DB, Merchant RC, et al. Inferior vena cava collapsibility detects fluid responsiveness among spontaneously breathing critically-ill patients. J Crit Care. 2017;41:130-7.

22. Rathmann W, Scheidt-Nave C, Roden M, Herder C. Type 2 diabetes: prevalence and relevance of genetic and acquired factors for its prediction. Dtsch Arztebl Int. 2013;110:331-7.

23. Ahmed A, Campbell RC. Epidemiology of chronic kidney disease in heart failure. Heart Fail Clin. 2008;4:387-99.

24. Gigante A, Liberatori M, Gasperini ML, Sardo L, Di Mario F, Dorelli B, et al. Prevalence and clinical features of patients with the cardiorenal syndrome admitted to an internal medicine ward. Cardiorenal Med. 2014:4:88-94.

25. Banerjee S, Panas R. Diabetes and cardiorenal syndrome: understanding the "triple threat". Hell J Cardiol. 2017;58:342-7.

26. Xue Y, Xu B, Su C, Han Q, Wang T, Tang W. Cardiorenal syndrome in incident peritoneal dialysis patients: What is its effect on patients' outcomes? PloS ONE. 2019;14:e0218082.

27. Mann JFE, Ørsted DD, Brown-Frandsen K, Marso SP, Poulter NR, Rasmussen $\mathrm{S}$, et al. Liraglutide and renal outcomes in type 2 diabetes. N Engl J Med. 2017;377:839-48.

28. Wanner C, Inzucchi SE, Lachin JM, Fitchett D, von Eynatten M, Mattheus M, et al. Empagliflozin and progression of kidney disease in type 2 diabetes. $\mathrm{N}$ Engl J Med. 2016:375:323-34

29. Dal Canton A, Fuiano G, Conte G, Terribile M, Sabbatini M, Cianciaruso B, et al. Mechanism of increased plasma urea after diuretic therapy in uraemic patients. Clin Sci (Lond). 1985;68:255-61.

30. Dutra SG, Paterson A, Monteiro LR, Greenwood MP, Greenwood M, Amaral LS, et al. Physiological and transcriptomic changes in the hypothalamicneurohypophysial system after 24 hours of furosemide-induced sodium depletion. Neuroendocrinology. 2020. https://doi.org/10.1159/000505997 Online ahead of print

31. Masella C, Viggiano D, Molfino I, Zacchia M, Capolongo G, Anastasio P, et al. Diuretic resistance in cardio-nephrology: role of pharmacokinetics, hypochloremia, and kidney remodeling. Kidney Blood Press Res. 2019:44:915-27.

32. Reddy YNV, Obokata M, Dean PG, Melenovsky V, Nath KA, Borlaug BA. Longterm cardiovascular changes following creation of arteriovenous fistula in patients with end stage renal disease. Eur Heart J. 2017;38:1913-23.

33. König P, Geissler D, Lechleitner P, Spielberger M, Dittrich P. Improved management of congestive heart failure. Use of continuous ambulatory peritoneal dialysis. Arch Intern Med. 1987;147:1031-4.

34. Pravoverov LV, Zheng S, Parikh R, Tan TC, Bhalla N, Reddy C, et al. Trends associated with large-scale expansion of peritoneal dialysis within an integrated care delivery model. JAMA Intern Med. 2019;179:1537-42.

35. Chuang M-K, Chang C-H, Chan C-Y. The effect of haemodialysis access types on cardiac performance and morbidities in patients with symptomatic heart disease. PLoS One. 2016;11:e0148278.

\section{Publisher's Note}

Springer Nature remains neutral with regard to jurisdictional claims in published maps and institutional affiliations.

Ready to submit your research? Choose BMC and benefit from:

- fast, convenient online submission

- thorough peer review by experienced researchers in your field

- rapid publication on acceptance

- support for research data, including large and complex data types

- gold Open Access which fosters wider collaboration and increased citations

- maximum visibility for your research: over $100 \mathrm{M}$ website views per year

At $\mathrm{BMC}$, research is always in progress.

Learn more biomedcentral.com/submissions 